\title{
La Unión Europea como actor en seguridad y defensa después de Lisboa: innovación institucional y retos estratégicos
}

La Política Exterior y de Seguridad Común de la Unión Europea (PESC) emergió con el fin de la guerra fría en el contexto de una aceleración general del proceso de integración europea. La aparición de nuevos tipos de conflictos en y cerca de Europa hizo crecer la necesidad entre los Estados Miembros de cooperar y actuar también en el ámbito militar. En las siguientes décadas, la UE ha buscado encontrar su identidad como actor global de seguridad entre el optimismo excesivo por parte de algunos políticos y analistas, el miedo de los EE.UU. de que la Política Europea de Seguridad y Defensa (PESD) se convirtiera en una alternativa a la cooperación transatlántica y la reticencia de los Estados Miembros de transferir competencias a la Unión en este ámbito tan simbólico de la soberanía nacional.

El Tratado de Lisboa fue motivado en gran parte por la necesidad de aumentar la capacidad de actuación internacional de la Unión Europea, a través tanto del nuevo Servicio Europeo de Acción Exterior como de la nueva Política Común de Seguridad y Defensa (PCSD). Sin embargo, a pesar de que el Tratado de Lisboa contiene importantes innovaciones institucionales, también hay factores que apuntan al mantenimiento del status quo: Los Tratados 'Lancaster House' entre Francia y el Reino Unido hicieron surgir dudas sobre si constituirían un complemento o una alternativa a la actuación conjunta de la Unión Europea. Asimismo, la crisis que tuvo lugar en Libia a partir del año 2011, particularmente la imposibilidad de generar un consenso entre los Estados Miembros que permitiese una intervención militar contra el régimen libio de Gadafi, dejó en evidencia la falta de un acuerdo estratégico básico en el seno de la Unión Europea. Más recientemente, deben destacarse los modestos resultados del Consejo Europeo de diciembre de 2013 en lo que respecta a la seguridad y a la defensa.

Estos son algunos de los factores que indican que la innovación institucional contenida en el Tratado de Lisboa en cuanto a la actuación internacional de la Unión no se ha traducido en una mayor claridad y precisión en la estrategia común. De ahí la necesidad de analizar dónde está situada la Unión Europea en su desarrollo como un actor internacional de seguridad, tanto en lo referente al desarrollo de sus capacidades como a nivel estratégico. 
Con este motivo se organizaron las XVII Jornadas sobre la Unión Europea «Innovación institucional y retos estratégicos en materia de seguridad y defensa» en el seno del Instituto de Estudios Europeos y del Equipo de Investigación «Integración Europea» de la Universidad de Deusto en noviembre de 2014. Pues bien, este número especial de los Cuadernos Europeos de Deusto recoge los trabajos de investigación más destacados que fueron presentados en dichas Jornadas.

En el primer artículo, José Luís de Castro Ruano traza la evolución de la Unión Europea como actor en materia de seguridad y defensa desde sus inicios en los años 40 hasta hoy día, poniendo el énfasis en la situación actual. Se investiga por qué coincide el actual anquilosamiento con la expansión de instrumentos jurídicos y políticos proporcionados por la entrada en vigor del Tratado de Lisboa y el incremento de la demanda de un mayor papel de la Unión Europea en materia de seguridad y defensa. No sólo se identifican una serie de factores que explican esta paradójica situación, sino también se analizan las últimas iniciativas de la UE para proseguir su fortalecimiento como actor, concluyendo que dejan más preguntas que respuestas con respecto a la futura política de seguridad y defensa y a la naturaleza de las misiones que llevará a cabo la Unión.

A continuación, Antonio Blanc Altemir analiza el entorno estratégico de la Unión Europea y los retos actuales a los que ésta debe enfrentarse. Dada su intensa actualidad y la magnitud de sus efectos, el conflicto de Ucrania es el hilo conductor de su análisis. Se aleja de la explicación simplista de una Rusia revanchista y se hace un análisis detallado y equilibrado de los eventos en Ucrania, proporcionando así al lector una visión nítida acerca de cómo el conflicto en Ucrania ha cambiado las relaciones en el triángulo Rusia-OTAN-Unión Europea, que es precisamente el entorno estratégico principal en el que actúa la Unión Europea.

Natividad Fernández Sola, por su parte, se centra en la innovación institucional de la Unión Europea haciendo especial hincapié en el impacto de la constitución y posterior evolución del Servicio Europeo de Acción Exterior (SEAE) en el desempeño de la Unión como actor en materia de seguridad y defensa. Se identifican varias debilidades en el funcionamiento de este Servicio. Igualmente, se proponen mejoras que no sólo pueden fortalecer la Política Común de Seguridad y Defensa, sino que también pueden contribuir a un debate más amplio sobre cómo debe reformarse el SEAE para un mejor funcionamiento. Se concluye que las reformas institucionales son una condición necesaria para lograr que la UE tenga un papel más decisivo, pero no suficiente, puesto que un mejor entendimiento político entre los Estados miembros sigue siendo un factor indispensable.

Este número especial concluye con el artículo de Francisco José Ruiz González sobre los actuales retos de la cooperación militar y del desarro- 
llo de las capacidades militares europeas. Se analiza tanto el diseño del aparato institucional de la Unión Europea, como el de las misiones llevadas a cabo. De esta manera se ofrece una visión clara de las lecciones aprendidas a lo largo de la evolución histórica de la PCSD, así como de las diferentes opciones existentes en cuanto al aumento de las capacidades militares de la Unión. Se concluye este trabajo con cuatro recomendaciones para optimizar las capacidades existentes y afirmando que se puede aumentar el impacto de la actuación de la Unión, no sólo a través de la obtención de nuevas capacidades, sino también por medio de la especialización de funciones y de la integración de los programas de armamento.

Steffen Bay Rasmussen

Universidad de Deusto, septiembre de 2015 